\title{
BUMPS IN THE MED: LANDSCAPE EVOLUTION IN GALABRIA, ITALY
}

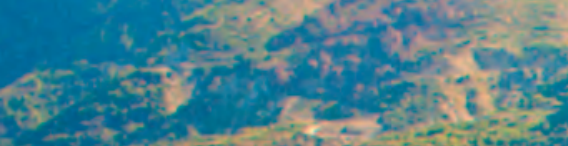




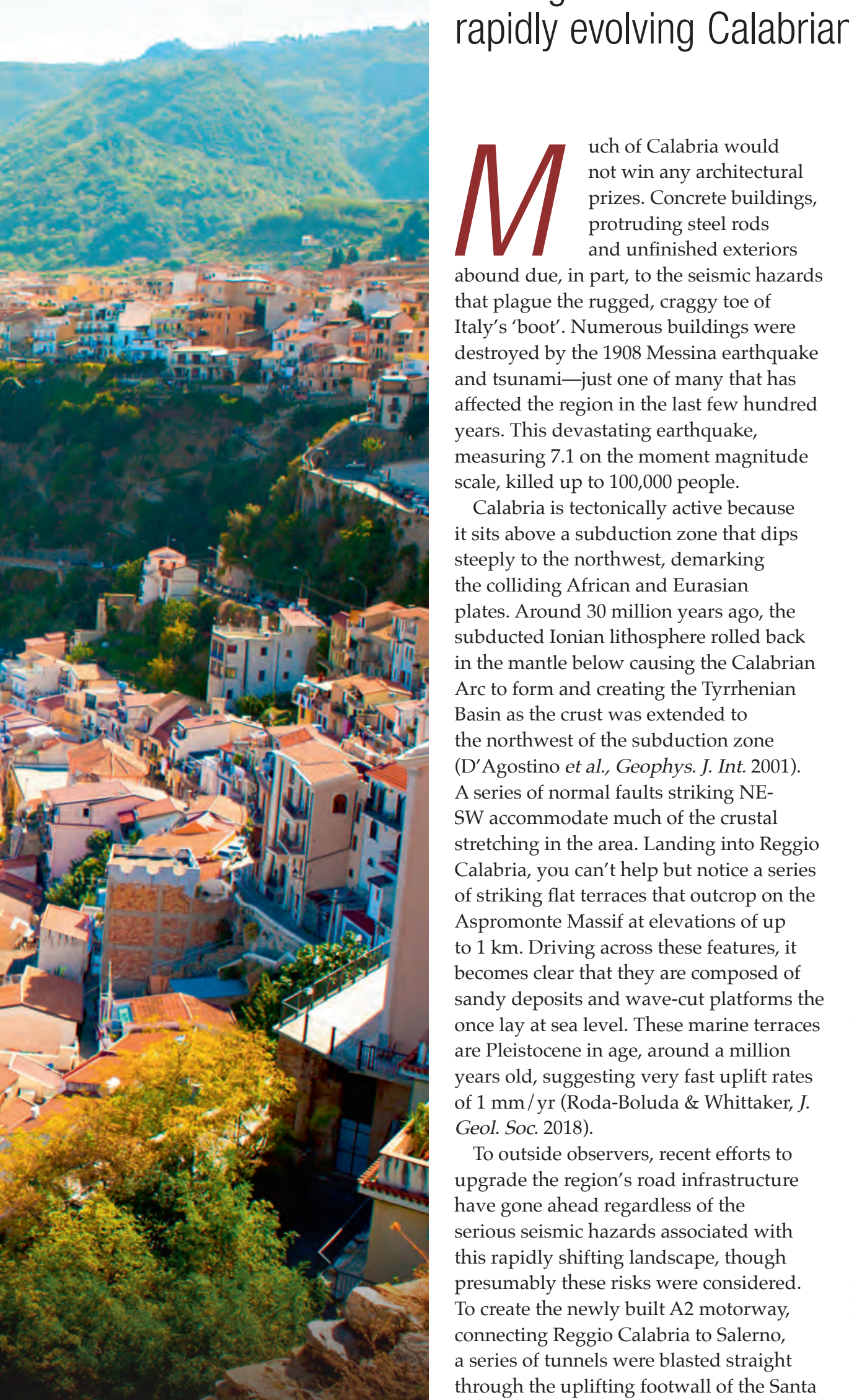

\section{Carla Pont investigates the tectonic and lithological controls on river profiles in the rapidly evolving Calabrian landscape}

Eufemia fault system, which ruptured in the catastrophic 1783 earthquake. Linking these tunnels is a spectacular $220 \mathrm{~m}$ strut frame bridge floating above the Favazzina River. The geomorphology of this river records the tectonic history of the Santa Eufemia Fault, and is one of three rivers that I used to gain clues into how this landscape is evolving.

\section{Clues in the landscape}

Plate tectonics, like many geological processes, cannot be directly observed. Instead, we must use measurements of Earth's magnetic, gravitational and seismic signals to gain insights, or we can gather clues from the landscape.

Next time you gaze across a landscape, view it as the surface expression of two competing vertical motions-uplift versus erosion. I am particularly interested in rivers because they hold vital clues to this delicate balance. A river in equilibrium with uplift and erosion will have a smooth concave-up profile. However, an established body of literature now shows that river profiles will develop prominent bumps-convexities in the long profile called 'knickpoints' - where the river steepens in response to a change in tectonics, climate or lithology (Rosenbloom \& Anderson, J. Geophys. Res. 1994; Stock \& Montgomery, J. Geophys. Res. 1999;

Sklar \& Dietrich, Geology 2001; Roberts \& White, J. Geophys. Res. 2010; and others). It is therefore possible to use knickpoints to model uplift histories with the streampower erosion model, which relates erosion to upstream drainage and bedrock erodability.

Knickpoints incise through bedrock, migrating upstream as an 'erosional wave'. However, the controls on the speed of knickpoint migration are poorly understood. For example, recent studies have shown that rivers crossing active faults in the Central Apennines, Italy and the Hatay Graben, Turkey respond much more slowly to tectonics than rivers in 

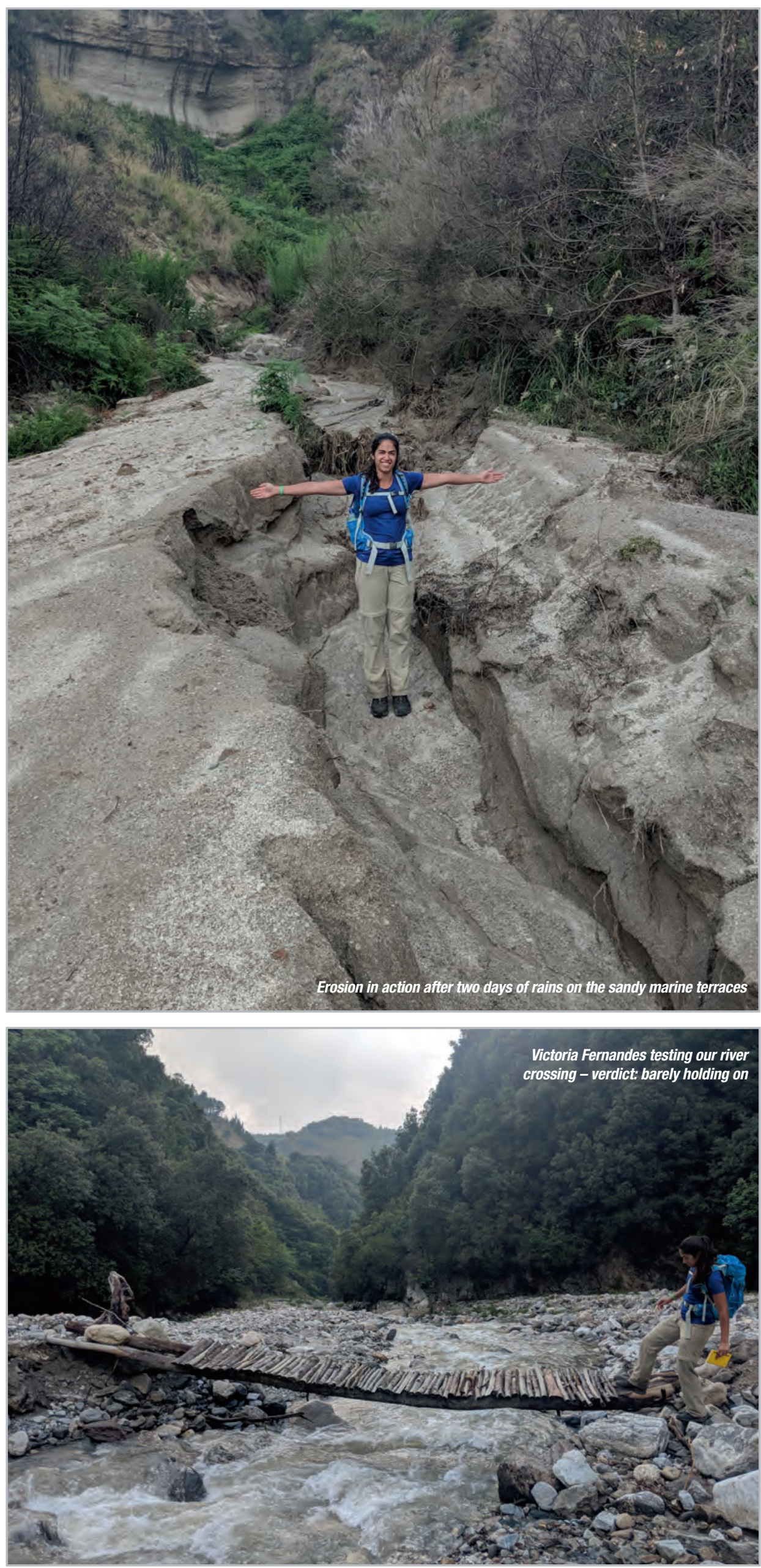

the Gediz Graben, Turkey (Whittaker \& Boulton, J. Geophys. Res. 2012; Kent et al., Earth Surf. Proc. Landforms 2017). However, the speed of knickpoint migration doesn't clearly correlate with differences in fault slip rates.

So, the aim of our expedition to Calabria was to gain a better understanding of landscape response times to tectonic forcing driven by active faults, and specifically to explore whether lithology or hydraulic geometry served as better explanations for knickpoint migration speeds than fault slip rates.

\section{Diverse waterways}

The trip proved to be exciting and thought-provoking. Calabria is a young, rapidly uplifting landscape, with numerous examples of rivers crossing active normal faults and excellent age constraints on uplift and fault-slip rates. Our small team comprised of myself, Alex Whittaker and Victoria Fernandes from Imperial College London. Over a period of two weeks, we collected rock-strength data and hydraulic measurements along three key rivers in Calabria, the Sciarapotamo, Favazzina and Valanidi rivers, which cross the Cittanova, Santa Eufemia and Armo faults, respectively. Alex had been to Calabria many times, so was an enormous help in contextualising the project. Our working hypothesis was that rivers would incise quickly into rocks with low bedrock strength, while knickpoints in steepened reaches of the river form where rocks had higher compressive strength.

We arrived in Calabria with our shortlist of three rivers to investigate. We spent the first two days on reconnaissance. A wealth of information can be gathered from satellite imagery, but we quickly discovered that some access paths to the rivers were an artefact of agricultural design or, more often, had simply been washed away by landslides. While the mountains of Southern Calabria rise to over $1,450 \mathrm{~m}$, taking a drive along the winding, high-mountain SP3 road made it abundantly clear that this landscape was crumbling fast. Metamorphic basement rocks were strewn across paths; landslides were clearly the norm in Calabria. First impressions suggested that we were dealing with incredibly weak, fractured rocks.

The three bedrock rivers we chose couldn't have been more different. The Sciarapotamo River, overshadowed by 
1-km-long viaduct, sat in a broad valley incising into granites. The Favazzina River, lying in a verdant v-shaped gneiss valley, was by far my favourite. Located close to the fishing town of Scilla, where we based ourselves, the river could only be accessed by long walk-ins from the flights of flat marine terraces forming the high topography. Farther south, the Valanidi River exposed calcarenites in the hanging wall of the Armo Fault with some beautiful deltaic sequences.

Highly urbanised and with minimal flowing water, it was difficult to imagine that devastating floods in the 1950s had destroyed towns along the Valandi Valley. 'Fiumara' is the local name for rivers in Calabria, meaning seasonal streams. These rivers are characterised by an ephemeral and torrential regime - in good times, benign, but after a severe rainy period, sudden and catastrophic floods quickly occur. Contrary to visions of hot Mediterranean summers, a few days into the trip torrential thunderstorms made working along riverbeds very difficult. It turns out that Calabria is one of the rainiest regions in southern Italy, with annual rainfall exceeding $1050 \mathrm{~mm} / \mathrm{yr}$. Our trusted Fiat Panda could navigate Calabria's steep narrow roads, but was halted when sandy offroad paths were washed away.

Despite inclement conditions, we collected extensive field data at 46 different localities. We gauged rock strength using the concrete industry's instrument of choice, the Schmidt Hammer. We made careful observations of the rock's fracture network and weathering state to quantify bedrock erodability. We measured river geometries using a laser range finder, from which we could later reconstruct stream power and flow velocities relative to the location of the fault. The aim was to gather enough data to understand what measures of rock strength were most important for erosional processes controlling landscape response times.

\section{Complex controls}

Some interesting conclusions came out of my initial field data. It seems that rock strength does not correlate with slope or channel width. So, if lithology doesn't control knickpoint formation in these Calabrian examples, knickpoints may instead reflect the temporal and spatial pattern of tectonic uplift, driven by active normal faults. Further analysis of data recording fracture orientation and spacing may improve our understanding of whether alternative measures of rock strength are important for bedrock erosion processes that control landscape response times.

Fieldwork in Calabria was an incredibly rewarding scientific endeavour. As a small team, we constantly debated ideas, attempting to decipher the mysteries of the Calabrian landscapes. Forked lightning, stuck cars and mosquito bites too numerous to count did little to dampen our spirits. Mt Etna formed a majestic backdrop through my favourite view had to be that from Scilla's castle walls, where we stood watching the sunset behind Stromboli. mists of the Messina straits, while

Carla Pont is a PhD student at Imperial College London and was a 2018 recipient of the Geological Society of London's Elspeth Matthews Fund

\section{ACKNOWLEDGEMENTS}

I am extremely grateful to the Geological Society of London's Elspeth Matthews Fund for supporting this expedition to Calabria

\section{FURTHER READING}

Roberts, G. G. \& White, N. (2010) Estimating uplift rate histories from river profiles using African examples. Journal of Geophysical Research: Solid Earth, 115(2), 1-24.

$\checkmark$ Roda-Boluda, D.C. \& Whittaker, A.C. (2017) (Structural and geomorphological constraints on active normal faulting and landscape evolution in Calabria, Italy. Journal of the Geological Society, 174(4), pp.701-720.

(Full references are listed online)

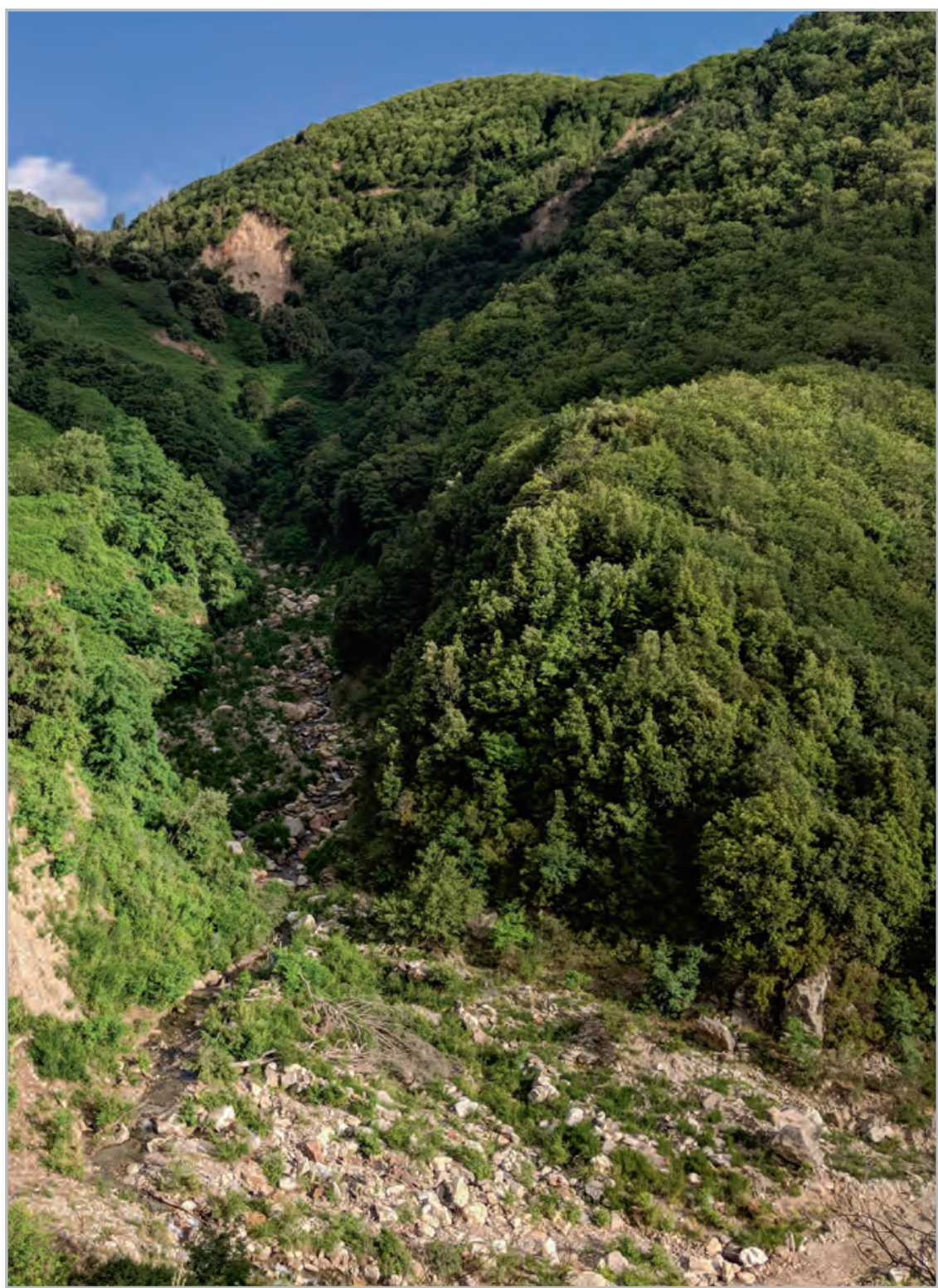

River re-incising into landslide debris on the Favazzina River 